\title{
A procedure for the identification of the seismic vulnerability at territorial scale. Application to the Casbah of Algiers
}

\author{
V. I. Novelli · D. D’Ayala · N. Makhloufi • \\ D. Benouar • A. Zekagh
}

Received: 17 February 2014 / Accepted: 10 August 2014 / Published online: 26 September 2014

(C) The Author(s) 2014. This article is published with open access at Springerlink.com

\begin{abstract}
One of the objectives of the PERPETUATE EU-FP7 project was to determine a sound approach to the quantification of the seismic vulnerability of historic centres at territorial scale. The procedure presented herein provides a ten steps guideline from how to select building samples in the area of study, to how to compute the buildings' seismic performance and finally how to evaluate rehabilitation decisions to reduce the seismic fragility of the studied typologies over an entire district or city. The procedure is illustrated in this paper by way of application to The Casbah of Algiers, a world heritage site composed of building clusters from the Ottoman to the French period. Pre-existing seismic damage, decay due to lack of maintenance and environmental factor and a urban irregular and complex lay-out make this application particularly challenging. A total number of around 150 houses, characterised by the most representative features of the Algerian historic construction, have been selected in collaboration with the Directorate of the Office for Management of Cultural Property of the Ministry of Culture,. The seismic Vulnerability Assessment Method (VAM) underpinning the 10-step procedure is is FaMIVE (Failure Mechanism Identification and Vulnerability
\end{abstract}

\footnotetext{
V. I. Novelli $(\varangle) \cdot$ D. D’Ayala

University College London, London WC1E 6BT, UK

e-mail: viviana.novelli@ucl.ac.uk

D. D'Ayala

e-mail:d.dayala@ucl.ac.uk

N. Makhloufi

Polytechnique School of Architecture and Urbanism (EPAU), Algiers, Algeria

e-mail: makhloufinacereddine@gmail.com

D. Benouar

Faculty of Civil Engineering, University of Science \& Technology Houari Boumediene (USTHB), BP 32, 16111 El-Alia/Bab Ezzouar, Alger, Algeria e-mail: dbenouar@gmail.com
}

A. Zekagh

Algerian Ministry of Culture, 16111 Alger, Algeria

e-mail: zekaghwahab@yahoo.fr 
Evaluation), a mechanical approach based on limit state analysis and kinematics, which allows computing collapse load factor, deriving capacity curves and determining fragility functions. As the approach identifies also the collapse mechanisms, it provides a base for choosing and evaluating the effects of strengthening interventions, which are rolled out at territorial level to improve the seismic performance of the whole sample. The effectiveness of the present procedure for the identification of the seismic vulnerability at territorial scale is discussed in the conclusions.

Keywords Seismic vulnerability $\cdot$ Masonry buildings $\cdot$ Historical buildings $\cdot$ Building cluster - Territorial scale

\section{Introduction}

One of the objectives of the PERPETUATE project, is the development of an approach for the identification of the seismic vulnerability at territorial scale by using a performance based method. The integrated methodology developed by the authors is summarised in a 10 steps procedure, providing guidance from sample selection to assessment of the efficacy of rehabilitation measures, focussing on the following specific tasks: 1) analysis of the urban layout, 2) identification of typologies and construction details; 3) choice of the representative sample for survey, 4) safety and conservation performance targets, 5) seismic hazard; 6) data collection; 7) data analysis; 8) computation of performance points, 9) definition of cumulative fragility functions; 10) rehabilitation strategies. The procedure from step 7 to 9 is run in further cycles to establish the effects of alternative strategies.

A variety of methods are available in literature to conduct the vulnerability assessment of masonry buildings. A number of these have been reviewed, to determine the method, which is suitable for the application of the procedure to a complex case study such as the one represented by Algiers. This will have to respond to the following criteria: 1) to be flexible enough in the description of the typologies; 2) to adapt to the complex geometry and irregular opening layout of the Casbah dwellings; 3 ) to be sufficiently concise and computationally efficient in surveying and analysing a relatively large number of buildings in relatively short time 4) to account the large variability in the building stock; 5) to allow the identification of , in-plane, out-of-plane and combined collapse mechanisms; 6) to determine the ultimate collapse and the performance drift 7) to correlate the structure capacity to the damage state 8) to establish the performance points for each building typologies, given a target earthquake scenario represented by a response spectrum.

The simplified Vulnerability Index Method, originally developed by Benedetti et al. (1988) and more recently revisited by Bernardini (2000); Giovinazzi and Lagomarsino (2004), Barbat et al. (2006, 2008), Vicente et al. (2014), is based on ranking a series of parameters, considered directly relevant to the seismic vulnerability of masonry structures, determining the hazard in terms of macro intensity scale and computing the expected damage using semiempirical methods on the basis of historic records. While this approach is adequate to asses urban area with frequent recurrence of damaging earthquakes, where a strong correlation can be defined among construction features, seismic intensity and observed damage. However, its application highly relies on past detailed records, which were not available for the historic Casbah. Moreover, the methodology, being dependent on the weight given to the factors used for the calculation of the vulnerability indexes for each building type identified in the area of study, might fall fowl of important epistemic uncertainties. This occurs, in particular, if the area under consideration is characterised by substantial variability in typologies and layout, as it is in the case of the Casbah. 
Generally, when historic records of damage are incomplete or inconsistent, recourse is made to analytical methods, which can substitute on site empirical evidence with a reliable behavioural model of building typologies. Nowadays, very sophisticated modelling environment are available in literature to simulate the post elastic behaviour of masonry structures subjected to lateral loading, such as TREMURI (Lagomarsino et al. 2013) and DIANA (Ramos and Lourenco 2004). These advanced F.E. approaches heavily rely on an accurate description of the buildings in terms of their geometry and availability of a relatively large number of material parameters, which are not usually investigated when vulnerability at territorial levels is conducted. These approaches are computationally demanding and a large number of different models are required to cover the large typological scatter observed in the Casbah. Moreover, some of the assumptions necessary in these modelling approaches, such as rigid floor diaphragms, good connection among orthogonal walls, panels governed mainly by in-plane behaviour, are not met in practice. On the other hand, these methods have the advantage of performing incremental dynamic analysis or push-over static analysis leading to the determination of capacity curves and drift thresholds, which can be used for the performance based assessment.

A third class of methods, with a level of modelling sophistication and computational burden, lower than the previous ones, is available in literature. These approaches, being able to establish mechanical relationships between construction details and damage, independently from statistical correlations of historic records, overcome the pre-condition of the vulnerability index methods. The earliest implementation of the these methods based on limit state analysis and the mechanism approaches are in VULNUS (Bernardini et al. 1990), and FaMIVE (D'Ayala and Speranza 2003; D'Ayala 2005) which fully complies with the performance assessment approach based on capacity spectrum and drift. These methods not only have the advantage, outlined above, but they also provide a large suite of possible collapse mechanisms, suited to masonry buildings with poor box behaviour and irregular openings layout, which will impair the standard pier-spandrel in plane frame-like assumption. The occurrence of different mechanisms is directly related to the specific constructional characteristics and details, as they are the collapse load factors that triggers them. This implies that typology, capacity and damage are explicitly correlated, without the need of using empirical statistical regression. The influence of epistemic uncertainty can be controlled and reduced by a prudent and sufficient choice of a representative sample of the building stock under analysis. The reliability of the output can hence directly be measured on the basis of the reliability of the input. Moreover FaMIVE is set as an open relational database, which means that its data capture structure is flexible and can accommodate specific constructional details and corresponding structural behaviours, found on site. This is then reflected in the addition of specific routines used to compute the relevant mechanisms, with the possibility of adding or removing feasible and plausible ones.

The Casbah of Algiers has a dense urban texture, similar to other typical medieval Muslim Maghreb cities such as Fez in Morocco and Tunis in Tunisia. Its shape and composition is the result of dense building agglomerates, mostly from the Ottoman period, grown organically around courtyards and wells, in a maze of streets and interconnected dwellings which lean against each other. The first and the last reported earthquakes in the Casbah of Algiers are dated in 1365 and 2003, respectively, with the most catastrophic seismic event recorded in the year 1716 (Amina et al. 2010). The observed damage which characterise the masonry houses of the Casbah is not readily attributable only to seismic events. Indeed a dearth of post-earthquake interventions following the 2003 event and lack of ordinary and specific maintenance have greatly increased the buildings' decay, exacerbated by continued deterioration of the drainage system of the hill and consequent loss of cohesion of the foundation soils. 
Since the typologies identified in the Casbah showed a number of features that were very unique, among which irregularity of windows lay-out, connections among adjacent buildings and internal porticoes courtyard, the present version of FaMIVE was updated to suite the new input fields required and the algorithm for the calculation of in-plane failure re-coded. The results of the application of this methodology are reported in Sect. 9 for the computation of the capacity curves and performance points, and Sect. 11 for the cumulative fragility curves and functions for the building typologies identified in the Casbah of Algiers. Finally, the effect of different rehabilitation options for the Algerian site are presented in Sect. 10 and discussed in Sect. 12.

\section{Analysis of the urban layout}

The Casbah of Algiers has been included in the UNESCO list of world Heritage sites in 1992 and the brief description states "the term Casbah, that originally designated the highest point of the medina during the Zirid era, today applies to the ensemble of the old town of El Djazair, within the boundaries marked by the ramparts and built at the end of the sixteenth century, dating back to the Ottoman period" (http://whc.unesco.org/en/list/565). Indeed previous settlements on the site include Phoenician, Carthaginian and Roman trading posts, besides the Berbers and Arab settlements, predating the Ottoman conquest of 1517 , but the Medina flourished during the Ottoman regency from 1517 to 1830, (Amina et al. 2010). After the catastrophic earthquake of the 1716, some houses were rebuilt but others were completely abandoned to their decay. The urban fabric was also substantially altered in parts during the French colonial period by opening of roads and addition of storeys over original structures. The most recent seismic event $(6.8 \mathrm{Mw})$ in 2003 with epicentre $60 \mathrm{~km}$ east from Algiers, caused 2,300 deaths in the capital and the total and partial failures of different buildings, which are still visible in the Casbah, since these constructions have been either completely abandoned or not rebuilt yet.

Among the attributes for the Outstanding Universal Value, which warranted its inscription and define its authenticity are "the [urban] form and conception (very dense urban planning), construction materials (earthen bricks, earthen and lime rendering, stone and wood) and also the use (residential, trading, cult) and popular customs. The survival of traditional architectural skills, notably in the building trades and architectural decoration is a major advantage in support of its Outstanding Universal Value (ref. http://whc.unesco.org/en/list/565). As far as the integrity of the site is concerned, the assessment carried out in 2009 confirms that "despite the changes and the earthquake risk experienced by the site, the Casbah of Algiers still retains its integrity." The assessment also refers to the relevance and appropriateness of the safeguard plans and restoration programme and actions put in place by the Office for the Management of Cultural Properties and Exploitation (OGEBC). The seismic vulnerability assessment carried out within the PERPETUATE project is part of the activities identified for the safe implementation of the safeguard plan to reduce the risk posed by future earthquakes.

The main streets of the Casbah of Algiers identify several irregular blocks crossed by very narrow streets, which rarely create a rectilinear grid on the map, Fig. 3. The composition of the block with irregular plot of diverse size and the strong interconnection of party walls means that an entire block may form a cluster of building, with a seismic behaviour which is highly influenced by the interactions among buildings and their relative position in the block. The behaviour of a building cluster is also considerably affected by the soil landform, which rapidly slopes towards the sea and amplifies the sliding potential of each house within the block, besides providing a very specific amplification pattern of any incoming seismic waves. 
Most of the issues, which characterise the Casbah have been investigated by an in-depth study, initiated after the earthquake in 2003 and completed in 2008, under the coordination of the Algerian Ministry of Culture. This study, carried by 25 teams composed by architects, geologists, sociologists, and economists, has been performed to develop the P.P.S.M.V.S.S: "Plan Permanent de Sauvegarde et la Mise en Valeur du Secteur de la Casbah d'Alger", a plan for the protection and valorisation of the Casbah of Algiers, which proposed urgent shoring measures, which were taken in 2010 by CNERU.

The Casbah of Algiers is composed by 2189 parcels, $83 \%$ of these are built, the remaining, being vacant, are in use as public assets or are not in use because debris of demolished houses still occupy the parcel, as reported in CNERU (2008), The total number of standing buildings is $1816,30 \%$ of these show an advanced state of deterioration, $50 \%$ a medium state of deterioration, $10 \%$ is in a state of ruins and $10 \%$ is closed or walled up, therefore their state of damage has not been inspected.

Different interventions have been performed from 2008 to 2010 to increase the safety of the population and to preserve the houses in the Casbah. Most of collapsed or demolished buildings after the earthquake of 2003 have been cleared up and new parking areas and public squares have been created. Moreover, $20 \%$ of the total number of buildings (CNERU 2008) was shored by using temporary wood props to prevent failures in overturning and wood frames to support sagging floors and roofs.

Within the activities of the PERPETUATE project, the Casbah has been surveyed during two visits in September and November 2010 with the aim to identify the areas which better represent the statistical and geographical distribution of building typologies within the Casbah and to evaluate the parameters which most affect the seismic performance of single buildings and building clusters.

The areas selected for the present study are shown in detail in Sect. 7. Due to the complex distribution of the selected buildings, data related to composition and shape of the block, position of the building within the block, presence of collapsed buildings in the block, which record information not only at building level but also at urban level, is collected and considered for the estimation of the seismic vulnerability of the Casbah.

\section{Identification of the building typologies and construction details}

According to Amina et al. (2010), three main buildings typologies can be identified within an urban block in the Casbah: (1) "Dar shebbak" with "wast Al-dar", patio, highlighted in red in Fig. 1a, positioned in the centre of the house, (2) "Dar shebbak" with "shebak" in which the "wast Al-Dar" the big large patio of Fig. 1a becomes a "shebak", a small internal patio covered by a grid, highlighted in red, Fig. 1b, created for ensuring ventilation and illumination to the house and for providing access to the rooms, (3) "Al-Alwi", house without patio, distributed in elevation around a staircase, highlighted in red in Fig. 1c.

Common buildings are from one-storey (older and poorer) to five-storey high (in most of the cases the last two floors are later additions of the French period). Buildings within the blocks were in some cases built all at the same time, and it is visible from the interlocking of the masonry work among common party walls, or in other cases, over time, with adjacent buildings having independent party walls and different floors height, even though no space might have been left between the façades. In a small number of cases, reinforced concrete frame buildings are also present in adjacency to masonry houses or above or inside original masonry buildings. This layout has direct implications on the seismic behaviour of the single building and the cluster, and leaves some of them at severe risk of hammering, as indeed observed (Muthukumar and Desroches 2004) 


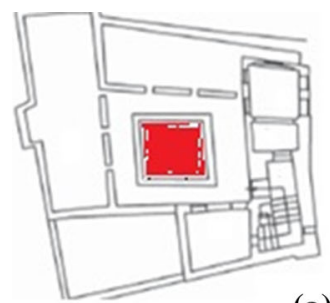

(a)

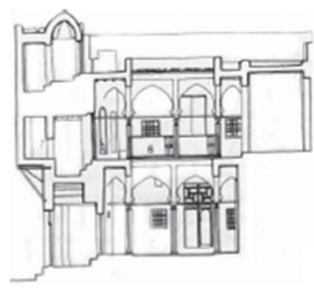

(a)

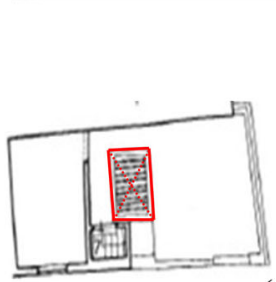

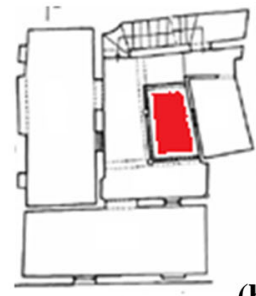

(b)

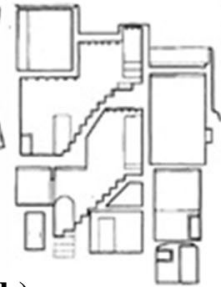

\section{(c)}

Fig. 1 Plan and section view of traditional house a "Dar shebbak" with "wast Al-dar", b "Dar shebbak" with "shebak and c "Al -Alwi" (images adapted from Missoum 2003)

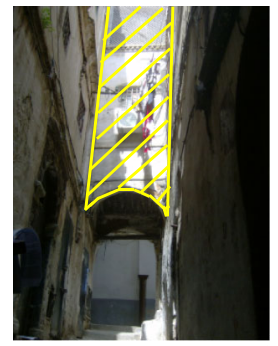

(a)

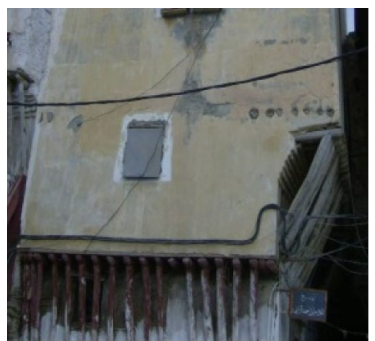

(b)
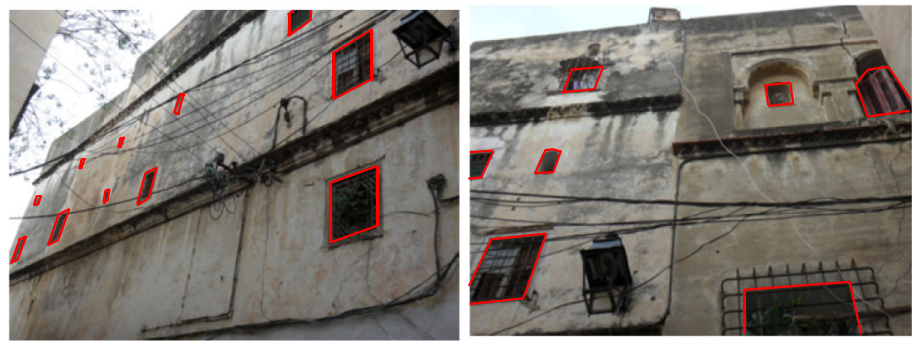

(c)

Fig. 2 a Sabat and b "q "bû", $\mathbf{c}$ opening layout of the façades in the Casbah of Algiers

The load bearing system, composed by sets of orthogonal walls, is made up of brickwork, or roughly hewn stone with randomly inserted bricks, or dressed stones with more regular brick courses. The wall thickness varies from $30 \mathrm{~cm}$ for the poorest quality to $90 \mathrm{~cm}$ or more for defence structures. Mortar is mainly in lime, but it has been also observed that mud mortar is used in some houses. The buildings in the Casbah are often characterised by an interesting architectonic element given by a structure built between the façades of opposite buildings facing on a narrow street. This element is called "sabat", Fig. 2a, or "q "bû" Fig. 2b, depending on whether it provides a total or partial roofed passageway. The original opening 
alignment, since several modifications are brought to the structures throughout the years, is frequently altered, indeed this is particularly evident from the irregular opening layout (Fig. 2c). Typical alterations to the original structures are the frequent addition of one or two storeys above the original roof level. The original horizontal structures are timber floors and roofs, replaced in the early twentieth century by jack arches (steel profiles with shallow brick arches) and in more recently refurbished buildings by concrete slabs. In summary, four major groups of construction typologies have been identified in the Casbah of Algiers and they can been classified using the WHE-PAGER project taxonomy (Jaiswal et al. 2011) as follows: unreinforced fired brick masonry with timber floors (UFB3); dressed stones and bricks with timber floors (DS2); dressed stones and bricks with reinforced concrete floors (DS4); poorly hewn stone stones and bricks with jack arches (RS4).

\section{Selection of a representative sample}

Once the building typologies representative of the Algerian constructions have been identified and classified according to the WHE-PAGER project taxonomy (Jaiswal et al. 2011) as it is mentioned in the previous section, the selection of the building blocks used to estimate the vulnerability of the present case study has been carried by identifying a sample with a similar distribution of building typologies as initially observed. Care has also been taken, to include buildings with different level of deterioration due to lack of maintenance water ingress, resulting in loss of mortar and loss of integrity, which are the most common causes of decay for the Algerian constructions. Furthermore, in order to take into account the different building techniques observed in the Casbah, the building sample include buildings from different period of constructions, indeed the selected urban blocks are represented by buildings from the Ottoman period and French period.

Walled up or closed buildings and houses in a state of ruin, which represent the $20 \%$ of the total number of buildings, are excluded from this study. Furthermore, $11 \%$ of the total number of buildings, used for public services, according to the report by CNERU (2008), Table 1, is also excluded from the present work, as often belonging to typologies different from the most common typologies identified in the present case study. Hence, within the chosen building

Table 1 Occupancy of the buildings (in percentage respect to the total number of buildings in the Casbah)

\begin{tabular}{lc}
\hline Occupancy & $\begin{array}{l}\text { Number of } \\
\text { buildings (\%) }\end{array}$ \\
\hline Residential buildings & 89.21 \\
Administrative offices & 1.71 \\
Education (nurseries, schools and college) & 1.38 \\
Museums and cultural heritages & 1.05 \\
Religion (mosques, marabout, Koranic school) & 1.16 \\
Hospitals and clinics & 0.39 \\
Services equipment: parking, public markets, & 3.52 \\
post offices, agencies, hotels and motels & 0.22 \\
Sport & 0.50 \\
Military & 0.06 \\
Port & 0.83 \\
Public squares and gardens & \\
\hline
\end{tabular}




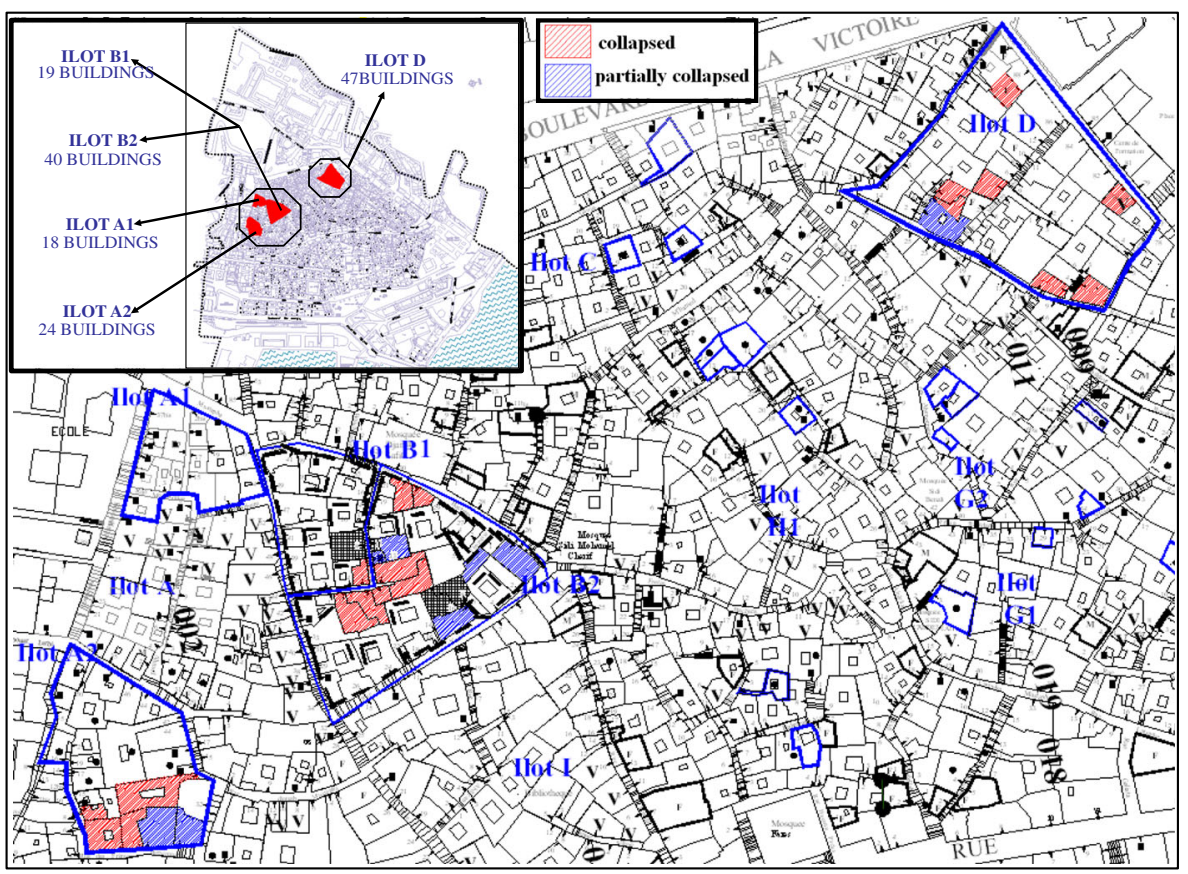

Fig. 3 The most representative blocks of the urban fabric of the Casbah (reference to the official map: Groupe CNERU, Plan de Recollallment, and Codification: ES1/DEG/01/09/CA)

sample, $93 \%$ of the buildings has a residential use, $4 \%$, has commercial activities at the ground floor and $3 \%$ characterised by an advanced process of decay, is vacant.

The level of reliability provided by FaMIVE in computing the vulnerability depends on the dimension of the sample given the variability in typologies observed. A representative sample should be at least $1 / 10$ of the total number of the buildings in the area under consideration. Since the total number of buildings is 1,816 and almost $30 \%$ of the total number of building is excluded for the reasons mentioned above, data for around 130 buildings are needed to estimate the vulnerability of the Casbah with a good level of accuracy.

Given the conditions above, the most representative blocks of the observed urban fabric were identified with the blocks A1 and A2, B1 and B2 and D, in Fig. 3 which includes around 150 buildings from the Ottoman regency to the French colonial period. The most common building typology is DS2 with a percentage of $87 \%$ against the $5 \%$ for the classes DS4 and RS4 and $3 \%$ for UFB3.

The selected buildings are characterised by different level of pre-existing damage, in particular $17 \%$ of the houses are totally or partially collapsed, $22 \%$ have significant damage and $19 \%$ light damage. During the survey, attention has been paid to record the construction details and the external actions which have caused the present deterioration. Medium and bad connection in the thickness of the walls is recorded in 35 and $15 \%$ of the buildings' sample respectively, low and medium level of maintenance of masonry for 24 and $19 \%$, respectively, high and medium level of water infiltration for 13 and $27 \%$ of the total buildings respectively and high and medium level of mortar loss for 22 and $23 \%$ of the total buildings respectively. In agreement with the level of alteration seen in the Casbah, $15 \%$ of the sample 
is characterised by buildings having vertical additions made with constructive techniques which are completely different from the ones used originally.

\section{Safety and conservation requirements}

Before conducting the analysis a choice should be made of the target performance level associated with the appropriate level of demand expected. In particular, as presented in D'Ayala and Novelli (2011), different target performance levels might be fulfilled, with reference to: (a) use and human life, (b) building conservation, (c) artistic assets conservation (Lagomarsino et al. 2011). This will be informed by the definition of importance coefficients related to both use and artistic value of the buildings, to define the safety and conservation objectives. Basically the procedure proposed allows for shifting the emphasis in the performance assessment from the life safety condition to the building collapse or the damage limitation condition in relation to the cultural value and use of the building and of its artistic apparatus. Once the objectives have been determined, then corresponding values of return period can be chosen to determine the reference hazard spectrum and compute the threshold drift associated with each performance level and damage states (D'Ayala and Novelli 2011). Considering the World Heritage site listing status, and the relevance that the listing gives to the urban fabric of the Casbah, all building should be given the same importance factor, to be applied to a conservation area, so it is assumed that $\gamma_{\mathrm{b}}=1$. However most of the residential buildings have no artistic asset of specific cultural value apart from the construction craft imbedded in their fabric, so the main target for the building should be the prevention of building loss and hence of collapse. Hence it is assumed that the target performance considering the conservation and asset requirement is collapse prevention for a demand of $10 \%$ probability of occurrence in 50 years or $475 \mathrm{RT}$ with a coefficient of $\gamma_{\mathrm{b}}=1$. On the other end, given the population density in the Casbah, (43,840 habitants according to CNERU 2008), and the high day time and night time occupancy rates, due to the mix residential and commercial use of many buildings, life safety becomes an important priority. Because there is no assumption of large crowding in any of the residential buildings considered, neither any of them is considered as strategic in the aftermath of an earthquake, the use coefficient $\gamma_{\mathrm{u}}$ should be set to 1 . Hence the target performance for use and human life is preservation of structural capacity for a demand of $10 \%$ probability of occurrence in 50 years or $475 \mathrm{RT}$, leading to a performance requirement stricter than the collapse prevention, which assumes some lateral capacity reduction in the presence of permanent deformation.

Once the target performance have been identified in qualitative terms the use the probabilistic uniform hazard curve allows to determine the PGA and the reference spectrum to be used to quantify the demand as shown in the next section. However in order to understand whether an asset or a family of assets fulfils the performance requirement, damage thresholds needs to be set, with which the performance can be compared. This can be done using diverse performance indicators. When using a capacity spectrum method, the lateral drift, either total or interstorey is an effective and synthetic parameter for measuring the state of damage, as it correlates directly to the ductility demand and hence to the post-elastic state of the structure. The FaMIVE procedure uses a collapse mechanism approach to derive capacity curves, directly related to the failure modes of a building. The post-elastic displacement is quantified in terms of stability consideration and bilinear or trilinear pushover curves are obtained. A review of the limited work available in literature aimed at correlating performance indicators and damage indicators to obtain capacity curves experimentally is reported in D'Ayala (2013). 
Table 2 Expected drift for different limit states, according to experimental evidence and EC8 guidelines

\begin{tabular}{lllll}
\hline Limit state & $\begin{array}{l}\text { In plane } \\
\text { experimental }\end{array}$ & $\begin{array}{l}\text { Eurocode 8 } \\
\text { part 3 }\end{array}$ & $\begin{array}{l}\text { Out of plane } \\
\text { experimental }\end{array}$ & Eurocode 8 part 3 \\
\hline Damage limitation (DL) & $0.18-0.23$ & & 0.33 & $0.8-1.2\left(\mathrm{H}_{0} / \mathrm{D}\right)^{\mathrm{a}}$ \\
Significant damage (SD) & $0.65-0.90$ & $0.46-0.60$ & 0.88 & $1.06-1.60\left(\mathrm{H}_{0} / \mathrm{D}\right)$ \\
Near collapse (NC) & $1.23-1.92$ & $0.53-0.8$ & 2.30 & 0 \\
\hline
\end{tabular}

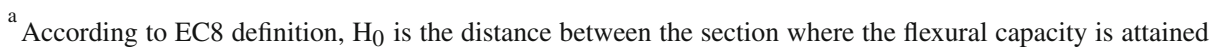
and the contra flexure point and $\mathrm{D}$ is the in plane horizontal dimension of the wall (depth); so that their ratio represents the slenderness of the pier or wall (D'Ayala 2013)

Using such data possible ranges of existence for the three drift limit states as defined by the EC8 (CEN 2005), due to either in plane or out of plane failure, are proposed in Table 2. These values are compared with the performance drift value obtained with the FaMIVE simulations for the damage thresholds of structural damage and near collapse corresponding to the two performance targets of life safety and collapse prevention defined above.

\section{Seismic hazard}

In establishing the seismic hazard of a region for an earthquake assessment at territorial scale, usually two different approaches maybe considered: either a probabilistic seismic hazard approach (PSHA) as proposed for instance by GHSAP (Giardini et al. 1999) and the more recent OPENQUAKE modeller (Monelli et al. 2012) or the deterministic scenario approach, directly correlated to specific events occurred in the region or foreseen events due to a particular fault structure. As discussed in D Ayala and Ansal (2012), a deterministic approach might be more relevant for the assessment of vulnerability of historic centres, as, if the seismicity of the area is well known, a credible earthquake scenario can be developed with a satisfactory degree of reliability, and might be directly correlated to past and future performance of the building stock (Erdik and Fahjan 2006.)

The seismicity of northern Algeria, and specifically the region of Algiers, has only recently become the object of detailed seismological study, so that empirical and instrumental data form a relatively short catalogue. A list of historic and documented events is compiled in Table 3, edited from Hamdache et al. (2010) to include only events with destructive consequences in Algiers. As it can be seen from this list, at least one destructive event per century has occurred in the Algiers region since the devastating event of 1365 .

Studies conducted by Olivera et al. (2005), shows that the region of Algiers is exposed to values of PGA greater than $0.24 \mathrm{~g}$ for a $10 \%$ probability of exceedence in 50 years as shown in Fig. 4 (Peláez et al. 2006). Based on seismogenic studies and ground motion models defined by Meghraoui et al. (1988), Boudiaf (1996) and Geomatrix (2006), Ait Meziane (2012) developed a standard PSHA for rock site conditions with focus on the historical site of the Casbah in Algiers (reference coordinate 3.05E-36.78N). Local site amplifications were not considered, due to the lack of detailed stratigraphic information. Figure 5 shows the hazard curves for each ground motion prediction models and Fig. 6 shows the computed mean hazard curves for PGA and spectral acceleration at various natural periods, at the considered site. These curves reflect the high seismicity of the region of Algiers and indicate that for the commonly-used return period of 475 years the expected mean ground motions are: PGA $=$ $0.37 \mathrm{~g}, \mathrm{SA}(0.2 \mathrm{~s})=0.90 \mathrm{~g}, \mathrm{SA}(0.5 \mathrm{~s})=0.57 \mathrm{~g}, \mathrm{SA}(1.0 \mathrm{~s})=0.28 \mathrm{~g}, \mathrm{SA}(2.0 \mathrm{~s})=0.11 \mathrm{~g}$. 
Table 3 Catalogue of historic events with destructive consequences in Algiers (adapted from Hamdache et al. 2010)

\begin{tabular}{llllllll}
\hline Date & Time & Longitude & Latitude & Depth $(\mathrm{km})$ & Reported magnitude & Intensity & Location \\
\hline $01 / 03 / 1365$ & $18: 00: 00$ & 3.05 & 36.77 & - & - & X & Algiers \\
$04 / 05 / 1504$ & - & 5.6 & 37.4 & - & - & IX & N. Jijel \\
$09 / 22 / 1522$ & - & 2.5 & 36.91 & - & - & IX & N. Tipaza \\
$05 / 11 / 1624$ & - & 3.891 & 36.92 & - & - & IX-X & Dellys \\
$10 / 09 / 1680$ & - & 4.4 & 36.5 & - & - & IX & Tizi Ouzou \\
$02 / 03 / 1716$ & $02: 00: 00$ & 3.1 & 36.7 & - & - & X & Algiers \\
$03 / 02 / 1825$ & $07: 00: 00$ & 2.9 & 36.5 & - & - & X & Blida \\
$01 / 02 / 1867$ & $07: 13: 56$ & 2.833 & 36.467 & - & - & X-XI & Blida \\
$12 / 24 / 1920$ & $13: 06: 06$ & 3.1 & 36.967 & - & - & V & N. Algiers \\
$09 / 09 / 1954$ & $01: 04: 37$ & 1.467 & 36.283 & - & MS 6.7 & X-XI & NW Beni R \\
$09 / 04 / 1963$ & $05: 06: 42$ & 5.2 & 36 & - & Mb Lg 6.3 & - & SW Setif \\
$10 / 10 / 1980$ & $12: 25: 23$ & 1.447 & 36.153 & 5 & MS 7.3 & IX & Chlef \\
$10 / 29 / 1989$ & $19: 21: 52$ & 2.444 & 36.74 & 10 & MW 6 & - & N. Tipaza \\
$05 / 21 / 2003$ & $18: 44: 19$ & 3.72 & 36.819 & 15 & MW 6.9 & IX-X & Boumerdes \\
\hline
\end{tabular}

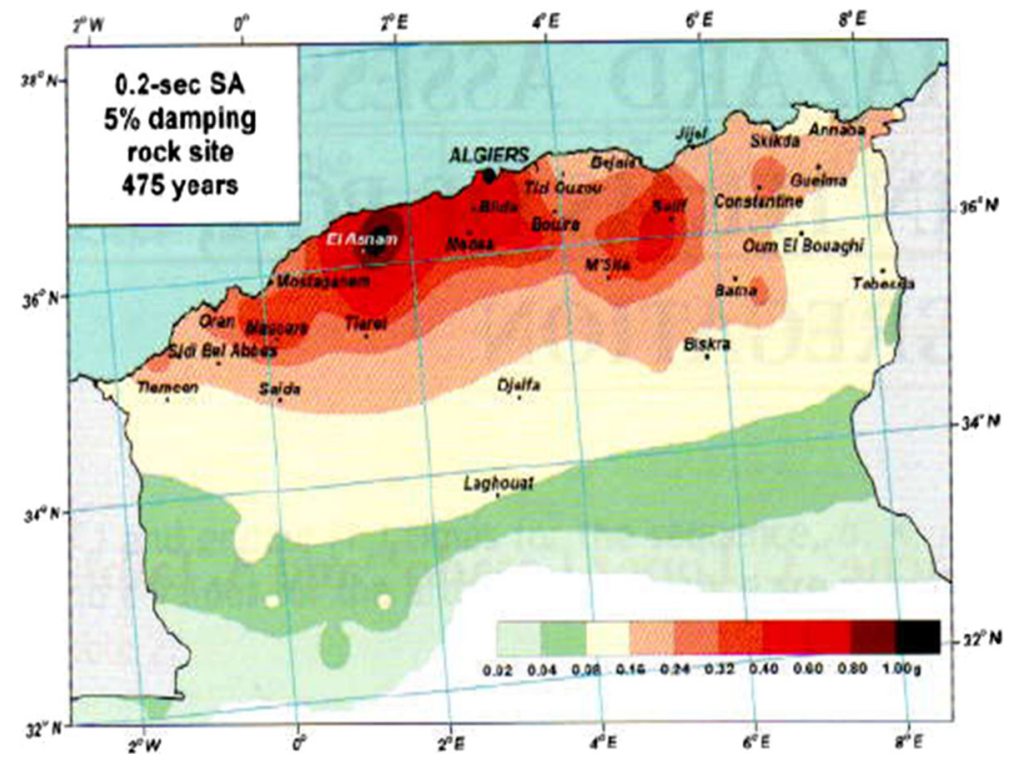

Fig. 4 Probabilistic SA values for roc, 0.2 s, damped at $\% 5$ and a return period of 475 years [Ref: Peláez et al. (2006)]

The final aim of PSHA is to produce the input load for the seismic assessment of buildings and given that the choice of assessment method is the capacity spectrum, a response spectrum for the area is the most appropriate way of representing the hazard in this context. The Uniform hazard spectra (UHS) for the rock site considered for a return period of 475 year computed with different GMPE are shown in Fig. 7 where it is clear that the scatter associated with using diverse ground motion prediction equations will affect structures with fundamental period 


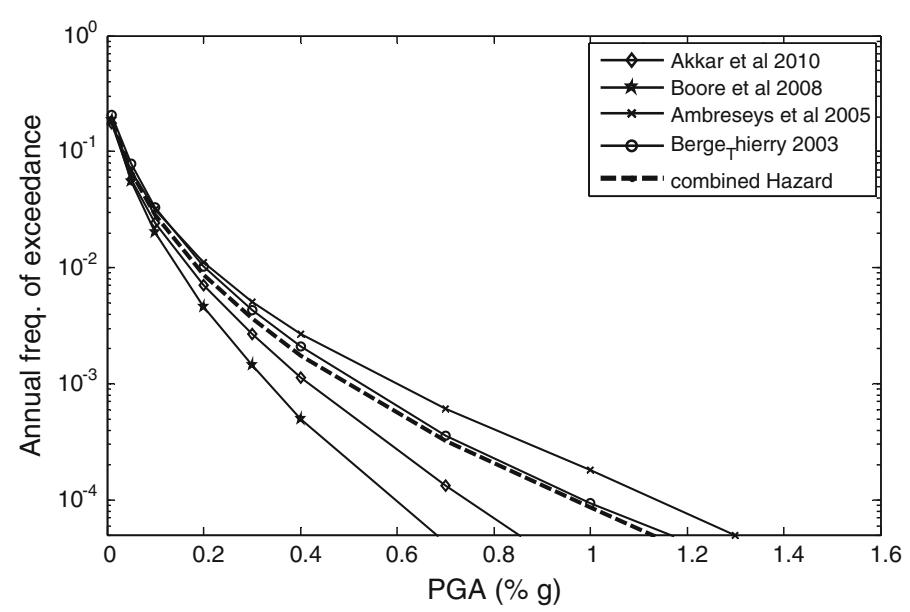

Fig. 5 Mean hazard curves for different GMPEs

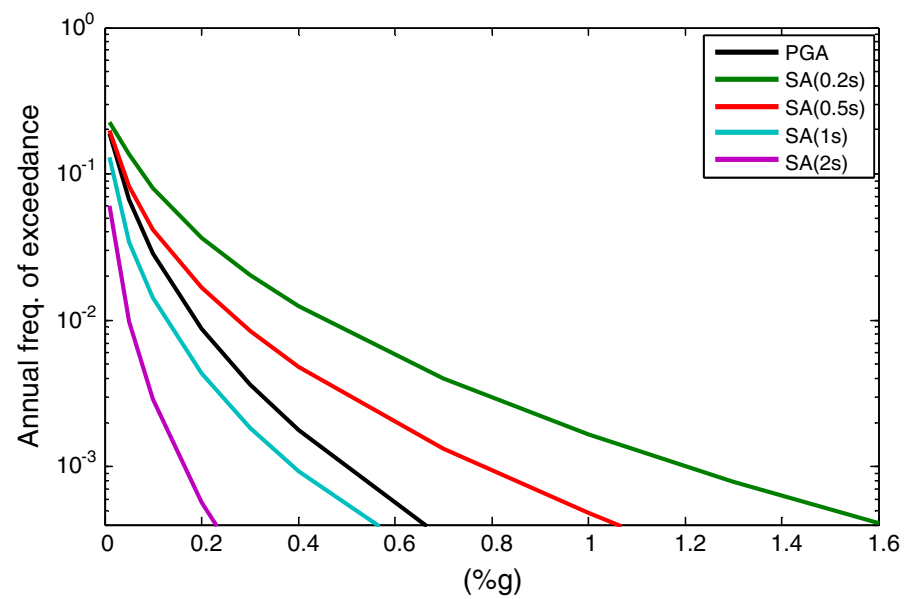

Fig. 6 Mean hazard curves at the considered site for PGA, SA $(T=0.2 \mathrm{~s}), \mathrm{SA}(\mathrm{T}=0.5 \mathrm{~s}), \mathrm{SA}(\mathrm{T}=1 \mathrm{~s})$ and $\mathrm{SA}(\mathrm{T}=2 \mathrm{~s})$

in the range of $0.10-1 \mathrm{~s}$, a range typical for masonry structures. In this study the spectrum used is the one obtained as a simple average from the four models, as there is no sufficient evidence to ascertain which model is more appropriate to this particular setting.

\section{Data collection}

The detailed inspection and data collection survey were performed in April 2012. The required data was collected by using the FaMIVE inspection form of Fig. 8. A manual, available on line ${ }^{1}$, which explains how each section of the inspection form should be filled, was specifically developed for the Algerian architects and engineers, who were trained to collect the data in the Casbah of Algiers. The form is implemented in an Excel spread sheet that is linked to

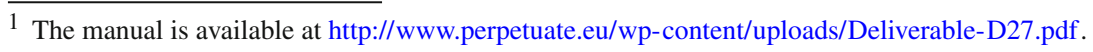




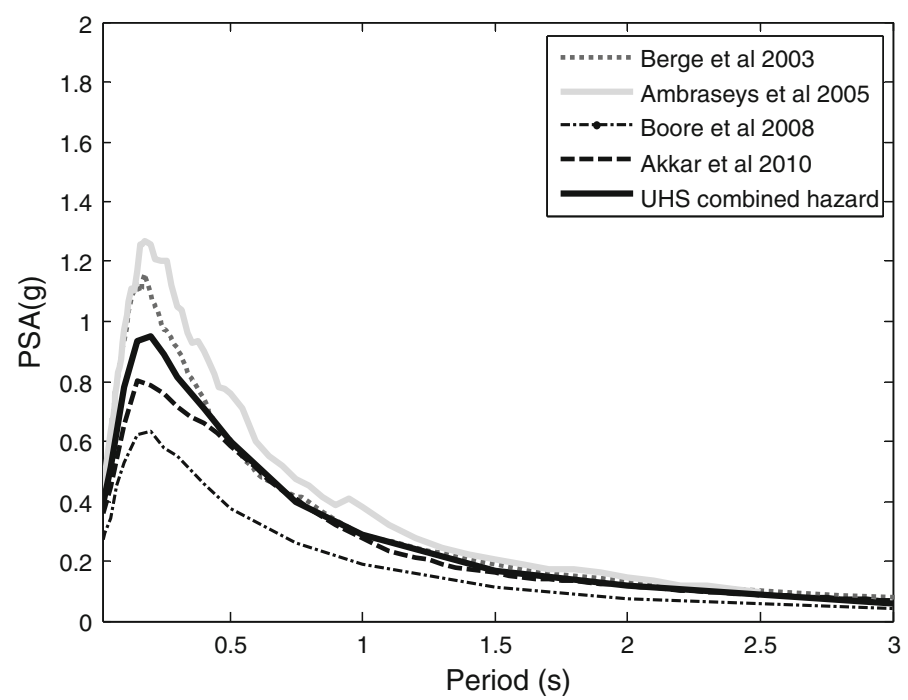

Fig. 7 Uniform hazard spectra for different GMPMs
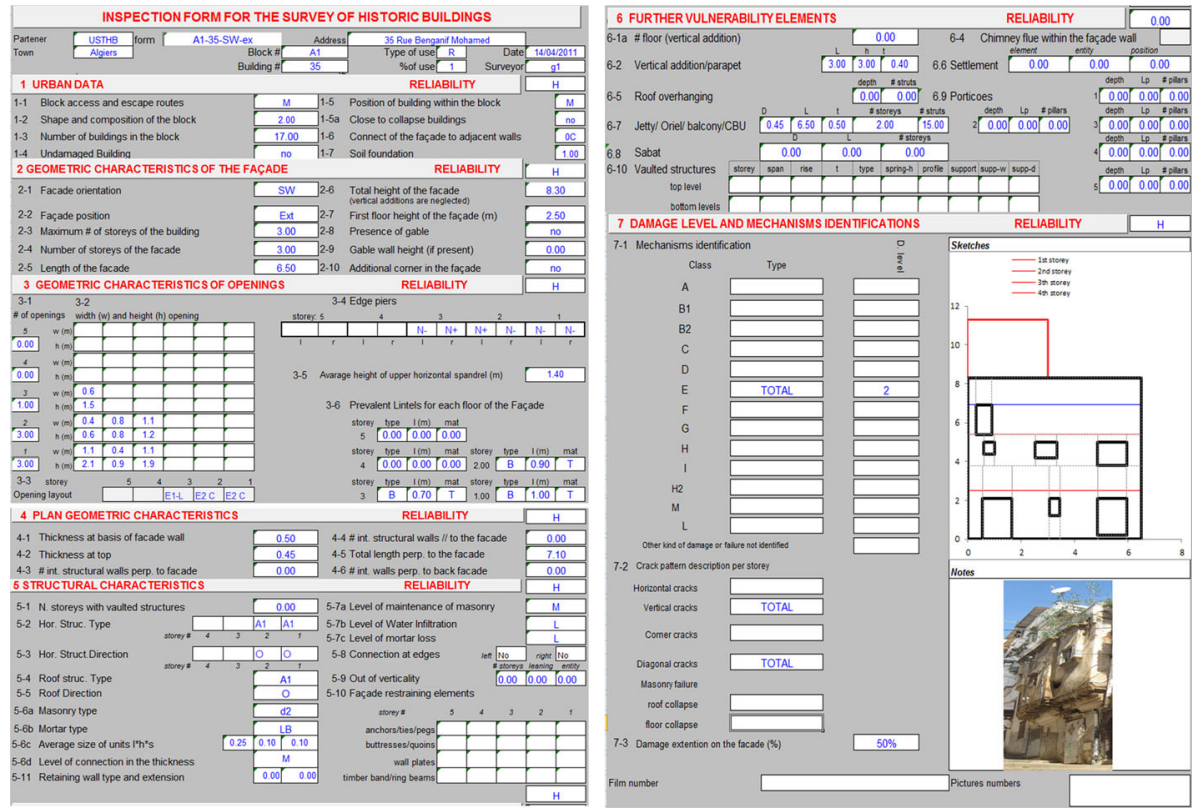

Fig. 8 Inspection form for data collection for the FaMIVE programme

algorithms written in Visual Basic which can be adapted to new typologies just by adding the necessary parameters affecting the seismic performance. The time required to complete one form, which is developed to collect data for a single facade, is initially one hour, reducing to half an hour for a trained surveyor with a good knowledge of the local characteristics of the building stock. A total of 233 forms were completed on site during the campaign in April 2012, by a team of 6 people (Fig. 9). 


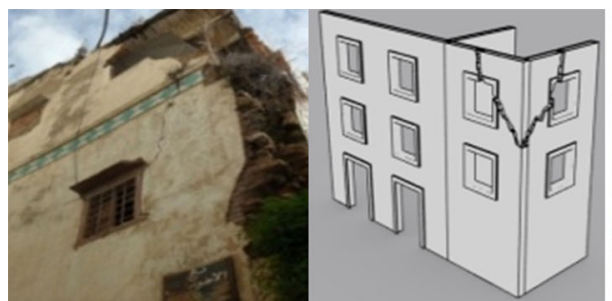

(a)

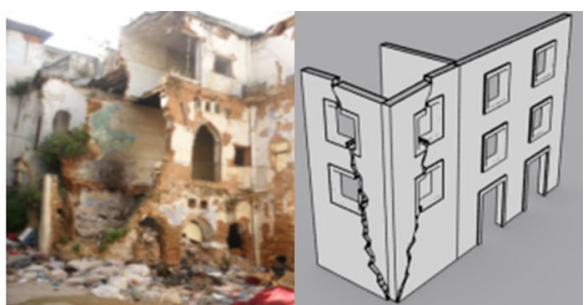

(b)

Fig. 9 Overturning a partial combined mechanism, b total combined mechanism

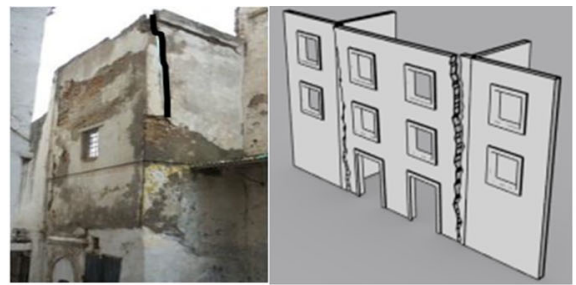

(a)

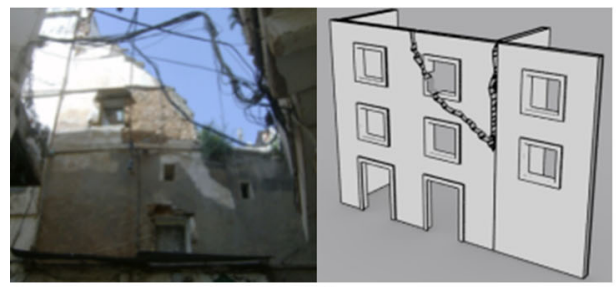

(b)

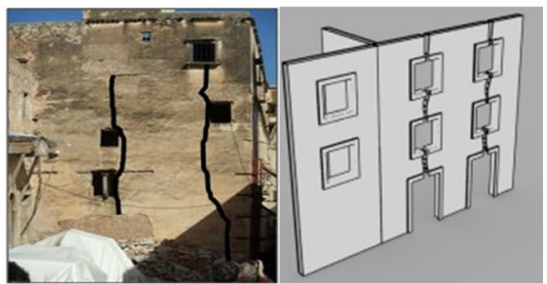

(c)

Fig. 10 Overturning due to a bad connection between facades, b bad connection between facades and bad connection between facades and horizontal structures, $\mathbf{c}$ bad connection between facades and internal bearing walls

An essential element of the survey is the identification of the level and quality of the connections among façades and party walls, adjacent façades and horizontal structures, as these constraints are the most critical parameters determining the mode of collapse. Given the presence on site of buildings with advanced crack pattern and in some cases fully developed mechanisms, it is possible to establish a correlation by observation between mode of failure and specific construction details. In general it was observed that façades failing for a partial or total overturning are usually characterised by either:

- Good connections between façades and bad connections between facades and horizontal structures (Fig. 10a, b), leading to the development of mechanisms which involve sets of orthogonal walls and are defined as combined mechanisms in Sect. 9;

- Bad connections between orthogonal façades (Fig. 10a), or between façades and horizontal structures (Fig. 10b), or between façades and internal bearing walls (Fig. 10c), leading to mechanisms which involve the failure of one façade only, defined as out of plane mechanisms in Sect. 9.

However, the observed crack pattern and collapses observed on site, although in some case are clearly traceable to the response to a seismic action; the lack of connections might be not the only cause of failure since pre-existing loss of integrity due to poor quality of the 

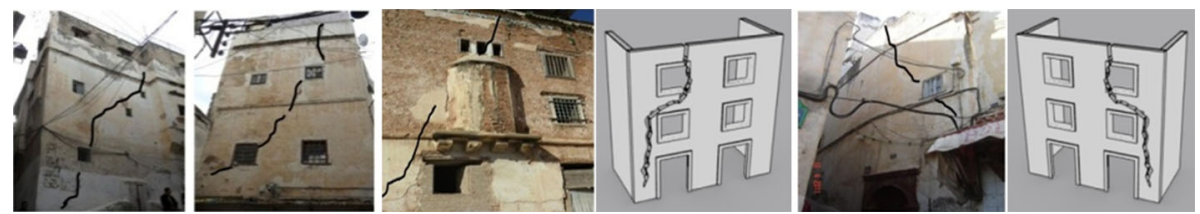

Fig. 11 In plane mechanism

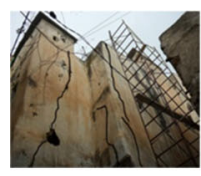

(a)

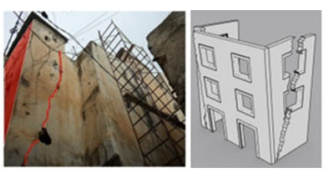

(b)

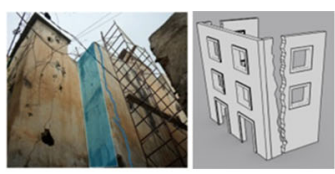

(c)

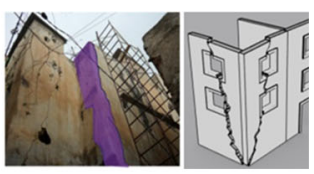

(d)

Fig. 12 Identification of all possible collapse mechanisms performed on site
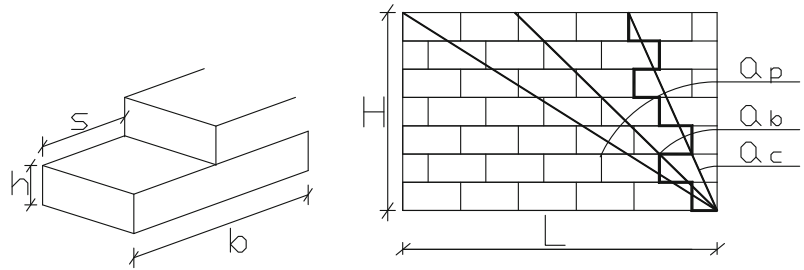

Fig. 13 Block dimensions and variable angle of crack in a pier

materials and the high level of water infiltration, or foundation failures might also induce cracks.

As for the in-plane failure, differently from what is usually observed in unreinforced masonry walls with regular openings, the occurrence of a recurring pattern of diagonal $\mathrm{X}$ shaped cracks in the spandrels or in the piers is not the most common case occurring in the Casbah. This is due to the irregular distribution and size of opening which leads to uneven distribution of stiffness and shear capacity among piers and spandrels, so that some might be more vulnerable than others, Fig. 11. Furthermore the piers might be failing in a combination of bending and shear, rather than just shear (Casapulla and D'Ayala 2006). For these reasons a different approach to the calculation of the in plane mechanisms is proposed in Sect. 8, by identifying the weakest load path in the façade leading to failure, rather than simply using the lateral capacity of the piers and assuming a rigid behaviour of the spandrels (or vice versa).

The identification of the collapse mode on the basis of the crack patterns observed on site is not always straightforward, as typically not all the cracks contribute to the ultimate mechanism, or the mechanism that eventually develops might be due to other weaknesses not immediately apparent from on street observation. The building in Fig. 12a, for instance, has a crack pattern which is particularly difficult to interpret since it conveys the possibility that more than one mechanism might be occurring on the structure. For instance, the red cracks in Fig. 12b point out that the façade in red is overturning and the wall with the red cracks is also failing for out of plane, as it is illustrated in the sketch.

However observing only the blue cracks in Fig. 13c the blue wall seems to be failing for overturning due to its bad connection with the adjacent façade with the blue cracks. Finally in Fig. 12d the purple cracks highlight a possible overturning of the corner of the building due to settlements or lack of connection between horizontal structures and the elevations. 
This example emphasizes the need to account all possible causes of a crack pattern observed on site with the aim of identifying all possible failure mechanisms, which affect the seismic vulnerability of the building under scrutiny (Novelli and D'Ayala 2014). To this end an analytical approach, using geometry and mechanical characteristics to determine the ultimate capacity and failure mechanism of a building is preferred to an empirical approach, which uses purely phenomenological evidence to assign modes of failure. Nonetheless an accurate record of the crack pattern is extremely valuable as a posterior check of the results obtained analytically and as guidance in choosing the strengthening strategy.

\section{Data analysis}

The programme FaMIVE, using the approach of limit state analysis for non-conforming materials, correlates collapse mechanisms to specific constructional features of the external bearing walls forming a masonry building. The analysis is static equivalent and quantifies the load factor multiplier as a percentage of gravity acceleration associated with each mechanism so as to determine a lower bound of the level of shaking which will trigger the onset of a specific failure mechanism. On this basis, FaMIVE produces a prediction of most probable damage modes and levels of vulnerability for individual or groups of buildings, in relation to expected levels of shaking at a site (D'Ayala and Speranza 2003; D'Ayala 2005).

As far as the current in-plane failure approach in FaMIVE, Casapulla and D'Ayala (2006) have demonstrated that a macroelement approach can be used to define the in plane load factor multiplier and collapse mechanism, in the hypothesis that the wall is constructed of brick-block masonry with a frictional behaviour. Indeed, it can be assumed that as a result of seismic loading a diagonal crack divides the wall into two macroelements: the bottom-left element that does not participate in the failure and the upper-right hand element that fails in sliding or overturning or a combination of the two (Fig. 13). Two different equilibrium conditions at failure develop depending on whether the angle of the crack, $\alpha_{c}$, is $\alpha_{p} \geq \alpha_{c}$ or $\alpha_{\mathrm{b}} \geq \alpha_{\mathrm{c}} \geq \alpha_{\mathrm{p}}$, where $\alpha_{\mathrm{b}}$ is the shape factor of the masonry unit calculated as ratio of $\mathrm{s} / \mathrm{h}$ (where $s$ is the overlap of the masonry units, $h$ is the height of one unit), and $\alpha_{\mathrm{p}}$ is the shape factor of the cracked portion of wall (H/L).

If the distribution of openings on a façade is regular, then the values of $\alpha_{p}$ and $\alpha_{c}$ are constant at each floor and among floor with the same opening heights, so that the stiffness and lateral capacity of individual piers and spandrel is easily determined and a simplified model with a prevalent rigid spandrel or rigid piers behaviour can be easily identified and a global lateral capacity computed. However when the opening layout is substantially irregular, as shown in Fig. 14, the division of the façade into pier and spandrels becomes blurred and the crack pattern generating the failure can follow a number of different paths. Hence an optimisation routine is needed to determine the path of least resistance within the façade, i.e. the one that will yield the minimum collapse load factor.

The geometric quantities used in the virtual work equations for the computation of the load factor multiplier for the in plane mechanism are shown in Fig. 14: $l_{s i}$ and $l_{p i}$ are the spandrel and pier width respectively; $h_{f i}$ and $h_{s i}$ are the interstorey and spandrel height respectively, while $h_{p i}$ is the height of the pier over which a crack will develop and $H_{g i}$ is the distance between the centre of gravity of the pier and the point where the cylindrical hinge forms, which coincides with the crack initiation point; $q_{f i}$ (or $q_{r}$ ) is the ith floor (or roof) load resultant, taken from the horizontal structures acting upon the portion of wall involved in the mechanism. The frictional behaviour of the masonry along the crack is given by frictional restraint from the pier, and frictional restraint from the spandrels. The frictional forces along 

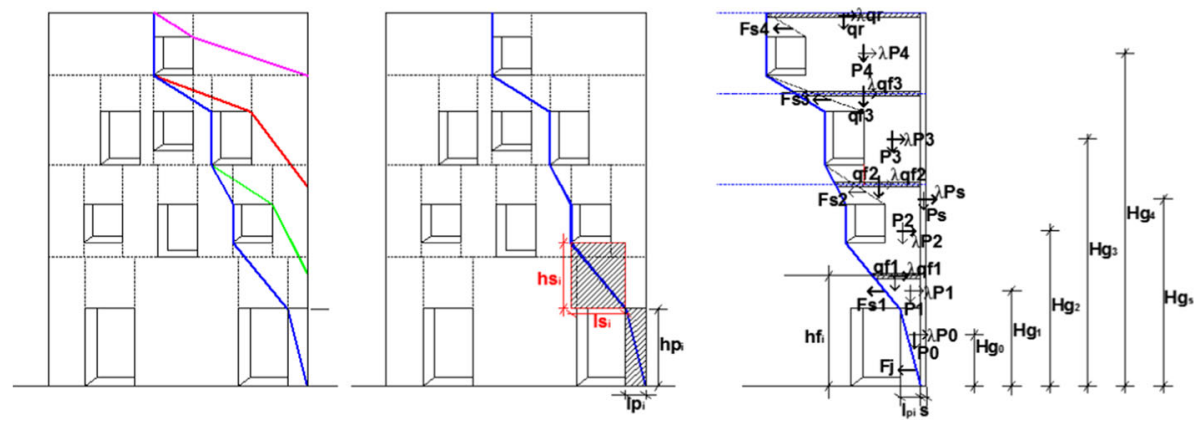

Fig. 14 Geometric variables, crack initiation points and forces involved in a façade with irregular opening layout where $\alpha b \geq \alpha c \geq \alpha f$. Adapted from Novelli and D'Ayala (2012b)

the crack in the pier, $F_{j}$ can be calculated by using Eq. 1 for $\alpha_{\mathrm{p}} \geq \alpha_{\mathrm{c}}$, independent from the crack angle, and Eq. 2 for $\alpha_{\mathrm{b}} \geq \alpha_{\mathrm{c}} \geq \alpha_{p}$; where $\gamma$ is the density of the masonry units and $t_{m}$ is the thickness of the façade.

$$
\begin{aligned}
& F_{j 1}=\left[q_{f i} h_{p i} \tan \alpha_{b}+\frac{\left(h_{p i} \tan \alpha_{b}+s\right) h_{p i}}{2} \gamma\right] t_{m} f \\
& F_{j 2}=\left[\tan \alpha_{b}\left(q_{f i}+h_{p i} \gamma\right)+\frac{\gamma}{2}\left(\frac{l_{p i} \tan \alpha_{b}}{\tan \alpha_{c}}-s\right)\right] \frac{l_{p i}}{\tan \alpha_{c}} t_{m} f
\end{aligned}
$$

The angle of the crack in the spandrel is taken as $\alpha_{c} \leq \alpha_{s}$, where $\alpha_{s}$ is the shape ratio of the spandrel. The interstorey heights, $h_{f i}$, are taken as an average for the whole building, except the first floor, for which different height can be accounted for. The spandrel heights are calculated using the building and opening geometry. The restraint force generated in the spandrel is computed by:

$$
F_{s}=\left[q_{f i} h_{s i} \tan \alpha_{b}+\frac{\left(h_{s i} \tan a_{b}+s\right) h_{s i}}{2} \gamma\right] t_{m} f
$$

The basic virtual work equation for any crack developed from the ith floor upwards can be written as:

$$
\begin{aligned}
\lambda_{1} \sum_{i}^{n} q_{i} h_{p i} n+\lambda_{1} \sum_{i}^{n} P_{i} H_{g i} \lambda_{1}+P_{s} H_{g s}= & \sum_{i}^{n} q_{i}\left(\frac{h_{p i} \tan \beta+s}{2}\right) \\
& +\sum_{i}^{n} P_{i}\left(\frac{h_{p i} \tan \beta+s}{3}\right) \\
& +P_{s} \frac{s}{2}+F_{j} \frac{h_{p i}}{3}+\sum_{i}^{n} F_{s i}\left(h_{f i}-\frac{h_{s i}}{6}\right)
\end{aligned}
$$

As for the spandrels, gravity loads and the overturning forces are also taken into consideration in the estimation of the value of the load factor multiplier $\lambda$, although they are not reported in the sketch in Fig. 14 and in the Eq. 4.

In the virtual work equations $\tan \beta$ is used to quantify the angle of the straight line between the crack initiation point and the point at which the crack meets the far edge of the pier accounting for the overlap $s$ of the first masonry unit. Crack angles greater than $\alpha_{b}$ are 
unlikely to form under the assumed conditions (Casapulla and D'Ayala 2006). $F_{s i}$ in Eq. 4 is the restraining force due to friction in the spandrels. An optimisation routine has been developed within the FaMIVE programme to find the solution that minimises $\lambda$.

\section{Definition of the performance points}

The FaMIVE procedure produces output in terms of collapse load factor and collapse mechanism. A capacity curve is then derived for each building using and equivalent single degree of freedom oscillator and stability consideration to determine the drift at which a given each damage state is reached. This procedure is explained in detail in D'Ayala (2013). Such capacity curves, developed with limit state approaches on data collected as explained in Sect. 7, are adequate to represent the average behaviour of a class or subclass of buildings, if standard deviation and aleatoric uncertainty are associated within the analysed building sample. Figure 15a shows the capacity curves obtained for the four major groups of construction typologies identified in the Casbah: (UFB3), (DS2), (DS4) and (RS4) defined in Sect. 3, while Fig. 15b shows the average capacity curves obtained considering buildings with the same class of failure mechanisms: Out-of-Plane mechanism (OOP), failure that involves overturning of one façade poorly connected with the orthogonal walls; Combined Mechanism (COMB), failure that involves overturning of facades well connected to walls orthogonal to them and poorly connected with horizontal structures; In-Plane mechanism (IP), failure that involves in plane failure of façades strongly connected with vertical walls and horizontal structures.

The capacity curves in Fig. 15a, b are computed for two cases, one by neglecting the contribution of the material's cohesion ( $c=0$ in Fig. 15) and the second by assuming that the cohesion of the original material has been increased to $0.25 \mathrm{~N} / \mathrm{mm}^{2}\left(\mathrm{c}=0.25 \mathrm{~N} / \mathrm{mm}^{2}\right.$ ) by using grout injections. It should be noted that although the increase in cohesion is the same for all building types, the average increase of base shear for each building typology is not the same, as the base shear depends on the distribution of collapse modes in each building class. For instance, the increase in cohesion benefits DS4 and RS4 more than the other two typologies (see Fig. 15a). As it can be seen from Fig. 15b, the increase in cohesion, in average terms, seems to have a greater effect on OOP failure modes and IP failure modes than on COMB failure modes. The increase in lateral capacity does not necessarily imply an increase in ductility.

(a)
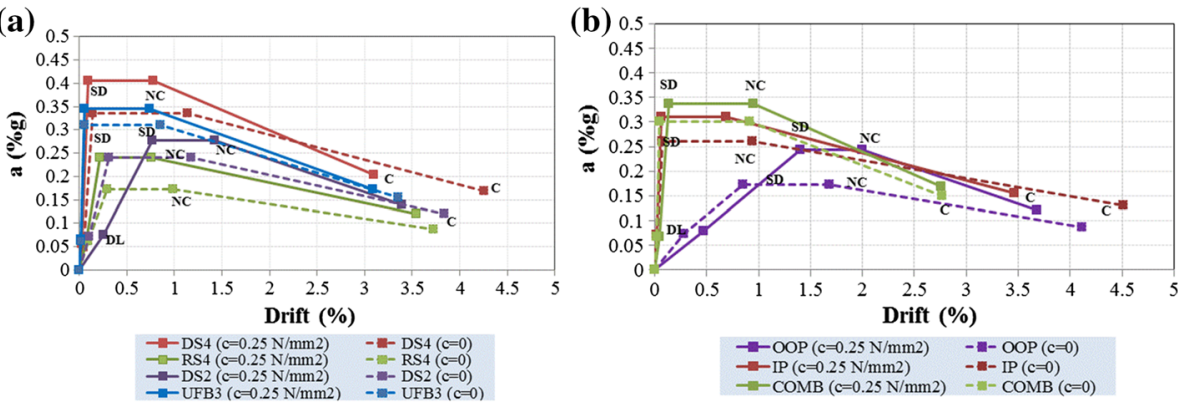

Fig. 15 a Comparison between the capacity curves for (DS2); (DS4); (UFB3) and (RS4) for the condition of $\mathrm{c}=0$ and $\mathrm{c}=0.25 \mathrm{~N} / \mathrm{mm}^{2} ; \mathbf{b}$ comparison between the capacity curves for in plane, out of plane and combined mechanisms for the total samples for the condition of $\mathrm{c}=\mathrm{s} 0$ and $\mathrm{c}=0.25 \mathrm{~N} / \mathrm{mm}^{2}$ 

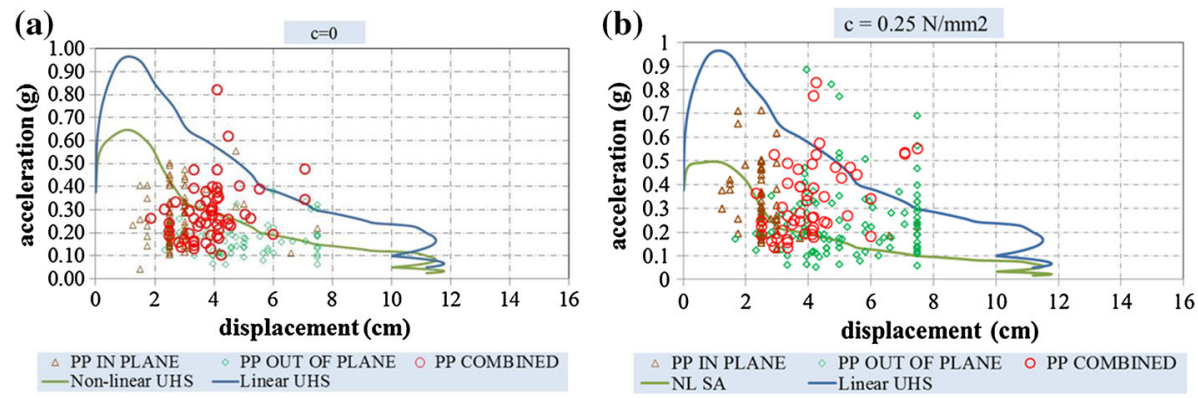

Fig. 16 Comparison between the performance points for the limit state of structural damage, associated to the significant damage condition in EC8 and the response spectrum linear and non-linear obtained from the UHS spectrum: $\mathbf{a}$ for building samples with $\mathrm{c}=0$ and $\mathbf{b}$ and for building samples with $\mathrm{c}=0.25 \mathrm{~N} / \mathrm{mm}^{2}$

The benefit of the increase in cohesion is more evident, when the performance points for each façade are compered. In Fig. 16a for $\mathrm{c}=0$, and Fig. $16 \mathrm{~b}$ for $\mathrm{c}=0.25 \mathrm{~N} / \mathrm{mm}^{2}$ the performance point for the limit state of structural damage, defined according to EC8 definition, is compared with the response spectrum obtained from the average UHS of Fig. 7. The nonlinear spectrum for a ductility value of 2 is also provided for reference. This is calculated using the N2 method approach (Fajfar 2000). Comparing the two diagrams the improvement in lateral capacity for the IP cases is evident as well as the improvement in performance of the COMB mechanisms affected façades, while many of the OOP facades representative points remain below the ductility spectrum, and hence in the unsafe zone. Although an increase in cohesion results also in an increase in tensile strength of the masonry (with the current friction model and tension cut-off the tensile strength is assumed as $f_{t}=0.75 \tau_{0}$, with $\tau_{0}$ representing pure cohesion) the major benefit is felt by the in-plane mechanism. The resulting increase in ultimate collapse load for the IP modes it means that there is a shift in critical mechanisms, corresponding to an increase in the number of OOP failure within the sample. The shift is approximately $33 \%$ from inplane failure to out-of plane failure, while the occurrence of combined mechanisms reduces by $8 \%$ on the total number of buildings as the other two modes of failure become more critical.

\section{Rehabilitation options}

In many historic centres in seismic prone areas, cross ties, inserted into the walls of the buildings, just below the floor level or above the openings, are a common feature to improve the connections between vertical adjacent walls or between walls and floors and to guarantee in plane failure to buildings. In the Casbah of Algiers only few buildings, $2 \%$ of the surveyed sample, are restrained with anchors. On the other hand, up to $10 \%$ of the total building stock of the Casbah is restrained by temporary wooden truss systems which form a buttress, preventing the overturning of the entire façade (Fig. 17a). For building facing on narrow streets an alternative shoring system, comprising a series of vertical composite posts connected transversally at every meter or so depending on the geometry of the façade, and contrasted to a twin system on the other side of the street, shown in Fig. 17b, is also frequently observed. The objective is to prevent overturning of opposite façades facing the same street while maintaining access by creating a safe passageway (Fig. 17c). 

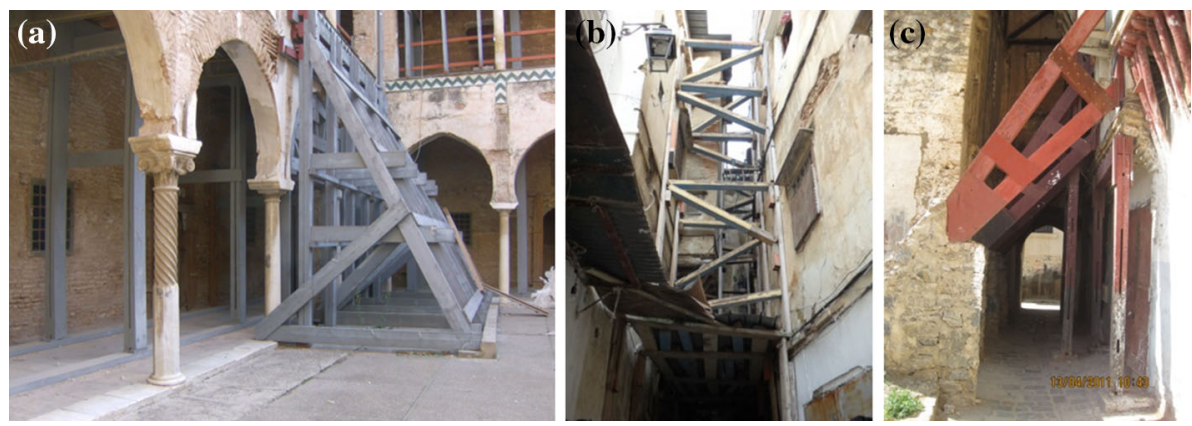

Fig. 17 a Shoring system made of wooden trusses used to prevent out of plane failure of masonry walls in The Casbah of Algiers, $\mathbf{b}$ shoring system applied to buildings facing a narrow street and $\mathbf{c}$ system of shoring also supporting the q'bu

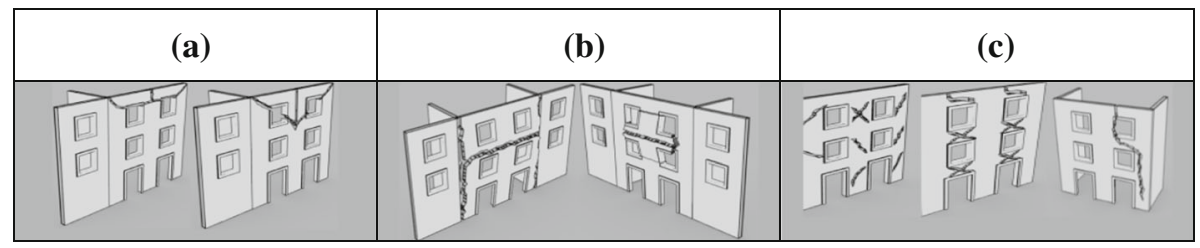

Fig. 18 Typical seismic failures occurring on buildings restrained by anchors a out of plane mechanisms: arch failure, $\mathbf{b}$ combined mechanism due to the presence of anchors, $\mathbf{c}$ in plane mechanisms

Given the prevalence of out-of-plane failures highlighted by the analysis and confirmed by the onsite observation, an effective strengthening strategy to increase the capacity of these buildings, while preserving their historical features, also meeting the requirements of low disruption, ease of implementation by local workmanship and modest cost, is the insertion of anchors in the wall to connect the facades to the party walls and floors. On the basis of these considerations, the effect of ties is investigated with the numerical procedure FaMIVE, to quantify the change in collapse load factor and ductility when ties are implemented to restrain the walls at roof level only at the edge of the facade. This distribution of anchors allows the mechanisms depicted in Fig. 18 to take place, preventing most of the out-of-plane failures and the combined failures. The in-plane failures are not affected by this type of intervention.

The effect of the ties is first investigated in the hypothesis of $\mathrm{c}=0$, Fig. 19, and then in the hypothesis of $\mathrm{c}=0.25 \mathrm{~N} / \mathrm{mm}^{2}$, Fig. 20. The use of anchors, as shown in Fig. 19a, produces a very noticeable increase in lateral capacity on average for buildings type RS4 and DS2, which had a majority of out-of-plane mechanisms, now prevented. However as seen in Fig. 19b, the comparison of the lateral capacity for the three types of failures shows a very modest average increase for OOP and IP, while the increase in lateral capacity for the COMB mechanism is quite substantial. It should be noted that, in average terms, there is a slight increase in stiffness for the elastic range and a decrease in ductility.

The use of ties decreases the percentage of buildings failing for overturning from 32 to $13 \%$, as it is highlighted in Fig. 21a, where the number of green rhombi are considerably reduced, respect to Fig. 16b. The percentage of buildings failing for COM collapses increase of $37.5 \%$, while the percentage of buildings failing for IP collapses increase only of $6 \%$, as a result of the overturning of entire facades being prevented. This points out that the use of 

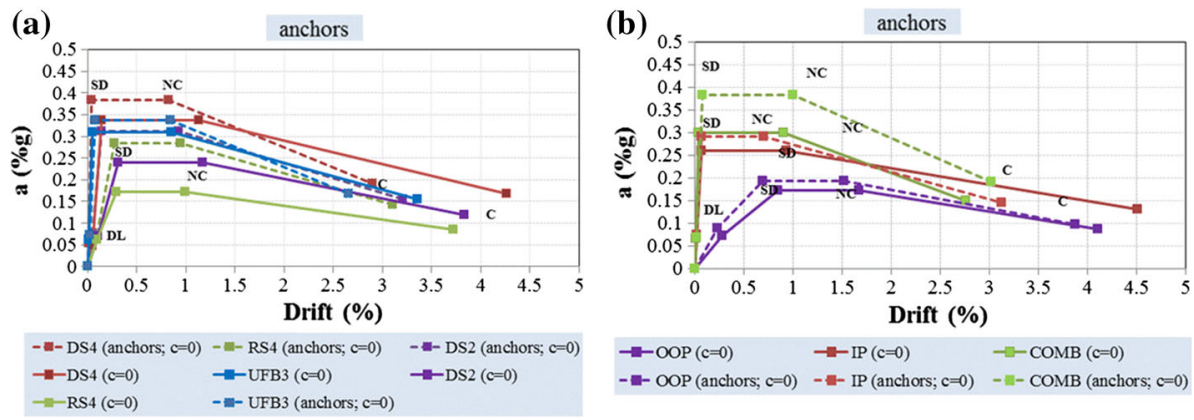

Fig. 19 a Comparison between the capacity curves for (DS2); (DS4); (UFB3) and (RS4) with and without anchors for the condition of $\mathrm{c}=0$; $\mathbf{b}$ comparison between the capacity curves for in plane, out of plane and combined mechanisms for the building samples with anchors for the $\mathrm{c}=0$
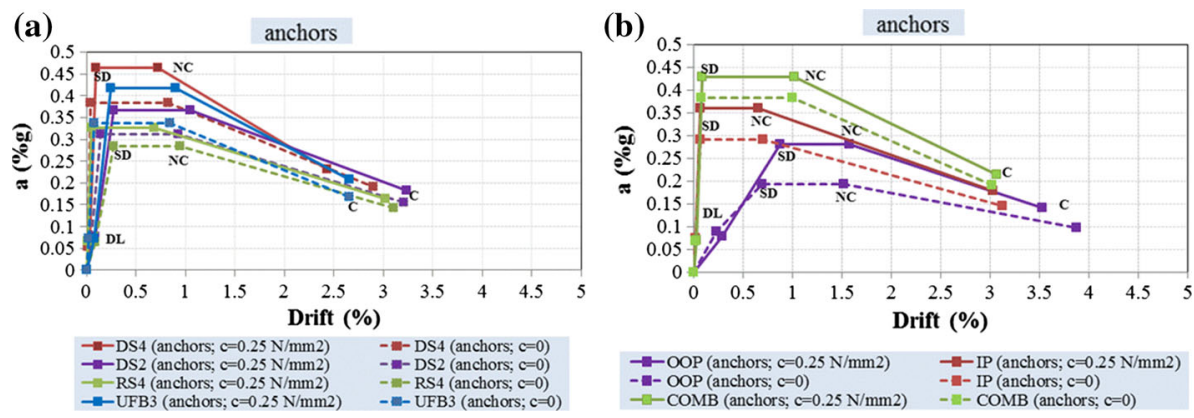

Fig. 20 a Comparison between the capacity curves for (DS2); (DS4); (UFB3) and (RS4) with anchors for the condition of $\mathrm{c}=0$ and $\mathrm{c}=0.25 \mathrm{~N} / \mathrm{mm}^{2} ; \mathbf{b}$ comparison between the capacity curves for in plane, out of plane and combined mechanisms for the building samples with anchors for the condition of $\mathrm{c}=0$ and $\mathrm{c}=$ $0.25 \mathrm{~N} / \mathrm{mm}^{2}$

ties allows not only improving the lateral capacity of the buildings but also favouring more ductile failure modes.

The grout injections in walls strengthened by ties further increase the lateral capacity of the building stock by an average of $30 \%$, as it is pointed out in Fig. 20, whether the sample is grouped in terms of typology or in terms of class of mechanism. Figure 21 shows the shift in mechanism types, first by introducing the anchors, with a clear decrease of OOP failure modes and increase of COMB failure modes, then with a decrease of IP failure and slight increase of OOP failure modes, when an increase in cohesion is also considered. The improvement of behaviour in the sample is clearly visible by the shift of points above the green line representative of the response spectrum for ductility of 2 , and an increase of points above the blue line representative of the elastic spectrum and hence representative of buildings, which will have an elastic behaviour for the considered scenario. It is however clear that a still considerable number of buildings will develop significant damage leading to in-plane mechanism, as denounced by the array of brown triangles.

\section{Definition of cumulative fragility functions}

The implementation of the strengthening strategies, not only shifts the value of lateral capacity and ductility of each façade and overall average behaviour, but also the proportion of 

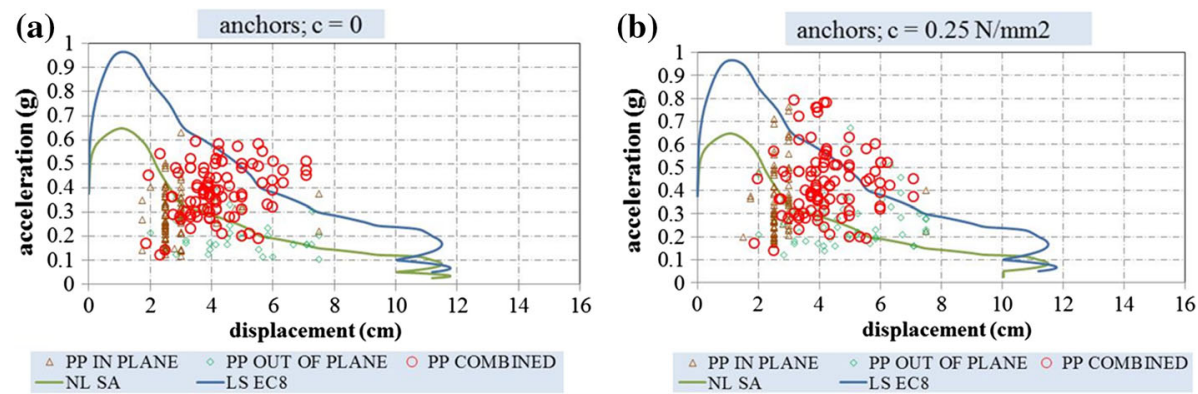

Fig. 21 Comparison between the performance points for the limit state of structural damage, associated to the significant damage condition in EC8 and the response spectrum linear and non-linear obtained from the UHS spectrum: a for building samples with $\mathrm{c}=0$ and anchors and $\mathbf{b}$ for building samples $\mathrm{c}=0.25 \mathrm{~N} / \mathrm{mm}^{2}$ and anchors

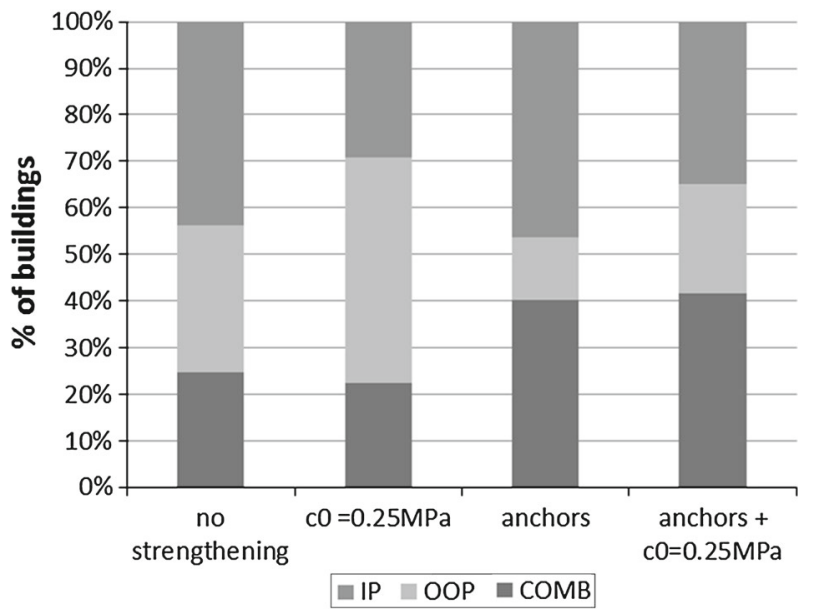

Fig. 22 Percentage of damaged buildings in combined (COMB), out of plane (OOP) and in plane (IP) mechanisms, in the hypothesis of $\mathrm{c}=0, \mathrm{c}=0.25 \mathrm{~N} / \mathrm{mm}^{2}, \mathrm{c}=0+$ anchors and $\mathrm{c}=0.25 \mathrm{~N} / \mathrm{mm}^{2}+$ anchors

occurrence and types of mechanism. The variation in occurrence of failure modes associated with the various strengthening strategies is shown in Fig. 22. It can be seen that the grouting resulting in an increase of cohesion, would minimise the number of in-plane failures, visà-vis an increase of overturning modes. On the other hand, the insertion of anchors, while minimises the occurrence of out-of-planes, results in an increase of in plane failure modes. A better balance is obtained, when both strengthening intervention are considered. Increasing the quality of the materials and improving connections in the walls, still leaves $23 \%$ of the total number of buildings prone to local out-of plane failures of the upper part of the façade, if unrestrained by connection to the roof's structures. To mitigate this vulnerability timber wall's plate and timber lacing might be adopted.

Cumulative fragility functions represent a synthetic and clear way to measure the improvement that can be obtained by the proposed strengthening strategies, as shown in Fig. 23, where the median value of the load factor multiplier for the four conditions are also included. A shift from 0.23 to $0.35 \mathrm{~g}$ is obtained as a median value. It is also interesting to analyse the shape of the cumulative curves. It can be seen that while the increase in cohesion provides a constant 

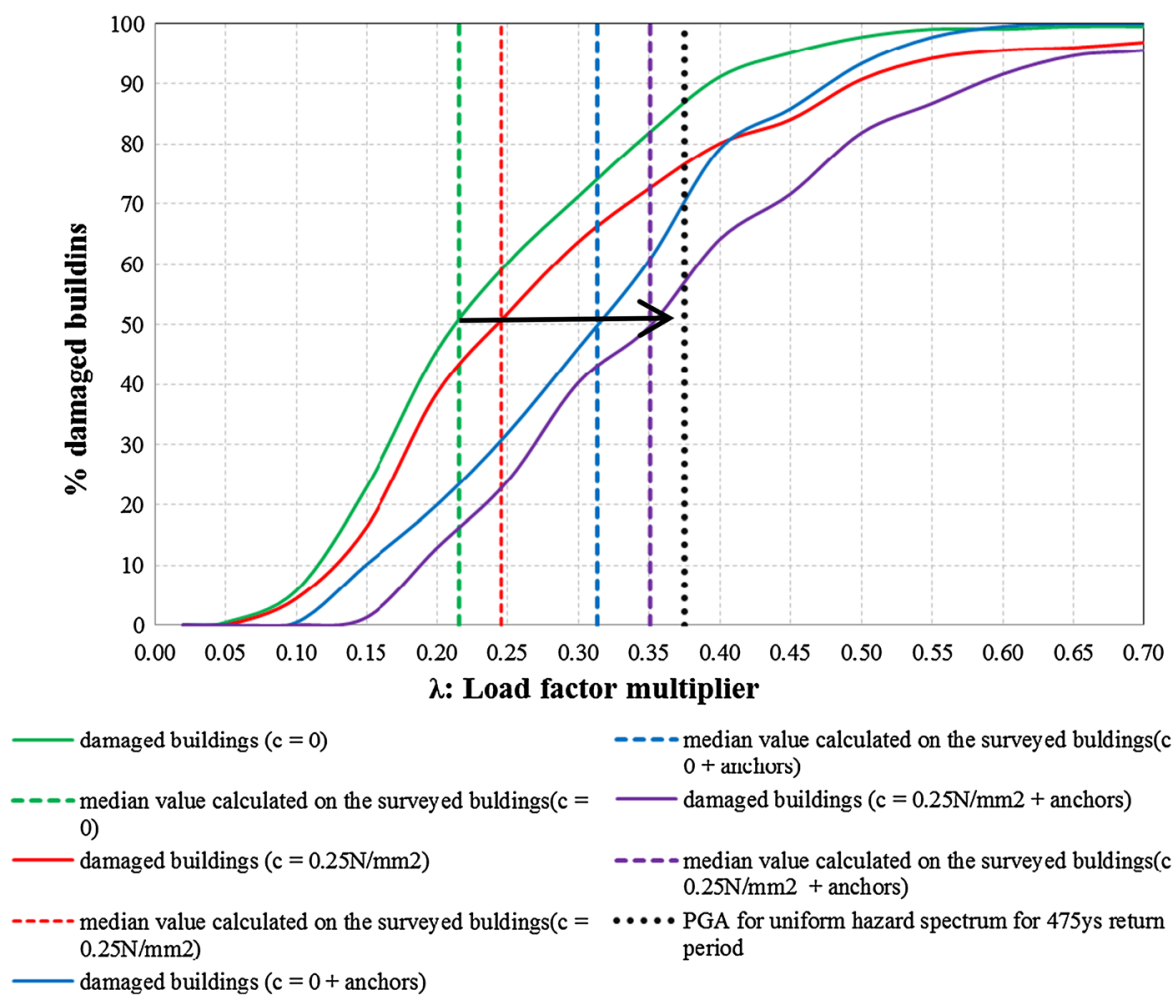

--- median value calculated on the surveyed buldings $(\mathrm{c}=$ $0+$ anchors)

- damaged buildings ( $c=0.25 \mathrm{~N} / \mathrm{mm} 2+$ anchors $)$

-- median value calculated on the surveyed buldings $(\mathrm{c}=$ $0.25 \mathrm{~N} / \mathrm{mm} 2+$ anchors)

-... PGA for uniform hazard spectrum for $475 \mathrm{ys}$ return period

Fig. 23 Load factor multiplier $(\lambda)$ distribution in the surveyed sample

improvement across the whole range, the insertion of anchors is particularly effective in the lower range of capacity, i.e. for structures with lower initial capacity, while is ineffective is the structure already exhibit a combined mechanism type of failure and relatively higher capacity. Figure 23 also shows that with reference to the PGA of the UHS for 475 years return period, the improvement in undamaged buildings, shift from 15 to $45 \%$ from unstrengthened to the case in which both strategies are implemented.

\section{Discussion and conclusion}

The effectiveness of the methodology developed for the identification of the seismic vulnerability at territorial scale in the framework of the Perpetuate project has been validated on the Casbah of Algiers. The application of the mentioned procedure has been successfully applied for the present case study since it has allowed identifying the major building typologies which represent the Algerian urban texture, estimating the seismic performance of the buildings selected for the present case study; and proposing strengthening interventions to their seismic behaviour.

FaMIVE has been successfully used for the purpose of the project and the aims of the mentioned approach, since this has allowed to study the large building blocks selected in the Casbah of Algiers on the basis of a small number of data easily collected on site according to the Sect. 7. Although in some cases it has been difficult to estimate the quality of connections 
Table 4 Increment of the lateral capacity in terms of percentage from $\mathrm{c}=0$ to $\mathrm{c}=0.25 \mathrm{~N} / \mathrm{mm}^{2}$, from $\mathrm{c}=0$ to $\mathrm{c}=0+$ anchors, from $\mathrm{c}=0.25 \mathrm{~N} / \mathrm{mm}^{2}$ to $\mathrm{c}=0.25 \mathrm{~N} / \mathrm{mm}^{2}+$ anchors, from $\mathrm{c}=0+$ anchors to $\mathrm{c}=0+$ anchors for the building typologies identified in the Casbah of Algiers

\begin{tabular}{llllll}
\hline & $\mathrm{ds} 4(\%)$ & $\mathrm{ufb} 3(\%)$ & $\mathrm{ds} 2(\%)$ & $\mathrm{rs} 4(\%)$ & Average $(\%)$ \\
\hline $\mathrm{c}=0==>0.25$ & 21 & 11 & 16 & 39 & 22 \\
$\mathrm{c}=0==\mathrm{c}=0+$ anchors & 14 & 9 & 30 & 64 & 29 \\
$\mathrm{c}=0.0==\mathrm{c}=0.25+$ anchors & 38 & 34 & 53 & 89 & 54 \\
\hline
\end{tabular}

Table 5 Increment of lateral capacity in terms of percentage obtained by increasing cohesion or and adding anchors

\begin{tabular}{lllll}
\hline & Ip (\%) & op (\%) & comb (\%) & Average (\%) \\
\hline $\mathrm{c}=0==>0.25$ & 19 & 40 & 12 & 24 \\
$\mathrm{c}=0==\mathrm{c}=0+$ & 12 & 12 & 28 & 17 \\
$\begin{array}{l}\text { anchors } \\
\mathrm{c}=0.0==\mathrm{c}=0.25\end{array}$ & 38 & 62 & 43 & 48 \\
+ anchors & & & & \\
\hline
\end{tabular}

between macroelements, or the quality of the materials, several analyses on the buildings with different constraint hypothesis have been carried out with FaMIVE. Moreover, most importantly, since FaMIVE provides not only the performance of buildings in terms of the lateral capacity, but also the collapse mechanisms, for which the buildings are most exposed, different strengthening interventions have been proposed on the basis of the vulnerability identified in the Algerian constructions. However, since the Casbah of Algiers is a world heritage site, the strengthening interventions have been also proposed according to the standards for the conservation of historical buildings.

The cumulative curves, which allow comparing the median values of the load factor multipliers, have been also a particularly useful tool to qualify and prioritise the type of interventions in relation to their effects on the building stock.

Tables 4 and 5 report the beneficial effect of using grout injection and anchors, in order to improve the performance of the Algerian constructions. The beneficial effect is highlighted by estimating in terms of percentage the variation of the lateral acceleration obtained by increasing the cohesion from $\mathrm{c}=0$ to $\mathrm{c}=0.25 \mathrm{~N} / \mathrm{mm}^{2}$ and using anchors. These tables point out that the minimum improvement is of $11 \%$ in the case of brickwork simply grouted, while the maximum increase is obtained when grout injection and anchors are introduced in rubble masonry structures, as highlighted by several studies, for instance Modena et al. (2011). The study shows that the use of grout injection to improve the mechanical properties of the material and ties to guarantee box behaviour of the buildings are effective strengthening strategies for the typologies of the Casbah.

However, it should be noted that a non-negligible number of buildings, more than $30 \%$ of the building sample, are still vulnerable to in-plane failure. A possible strategy is to further improve the shear strength of the material by stronger grouting, although it is seen on closer inspection that the failures are due to failure in flexure of slender piers, due to the irregular distribution of windows. Such vulnerability is difficult to mitigate without altering the architectural character of the buildings. While increasing flexural strength by means of near surface mounted or drilled through vertical bars, or improving confinement by means of fibre reinforce plastic strip wrapping are nowadays popular intervention, which might seem appropriate in the circumstances, it should be considered that they are very intrusive and irreversible. Moreover their efficiency in poor masonry fabric is still to be proven. It might 
be more suitable to consider traditional or innovative way of enhancing dissipation, rather than increasing strength.

Open Access This article is distributed under the terms of the Creative Commons Attribution License which permits any use, distribution, and reproduction in any medium, provided the original author(s) and the source are credited.

\section{References}

Ait Meziane Y, Djakab E, Benouar D (2012) Vulnerability of existing buildings: empirical evaluation and experimental measurements. Nat Hazards 62(2):189-206

Amina A, Abdessemed F, Benouar D (2010) Investigation of the 1716 Algiers (Algeria) Earthquake from historical sources: effect, damages, and vulnerability. Int J Archit Herit 4(3):270-293

Barbat AH, Pujades LG, Lantada N (2006) Performance of buildings under earthquake in Barcelona, Spain. Comput Aided Civil Infrastruct Eng 21:573-593

Barbat AH, Pujades LG, Lantada N, Moreno R (2008) Seismic damage evaluation in urban areas using a capacity spectrum based method: application to Barcelona. Soil Dyn Earthq Eng 28(10-11):851-865

Benedetti D, Benzoni G, Parisi MA (1988) Seismic vulnerability and risk evaluation for old urban nuclei. Earthq Eng Struct Dyn 16:183-201. doi:10.1002/eqe.4290160203

Bernardini A (2000) The vulnerability of buildings-evaluation on the national scale of the seismic vulnerability of ordinary buildings. CNR-GNDT, Rome

Bernardini A, Gori R, Modena C (1990) An application of coupled analytical models and experiential knowledge for seismic vulnerability analyses of masonry buildings. In: Koridze A (ed) Engineering aspects of earthquake phenomena, vol 3. Omega Scientific, Oxon, pp 161-180

Boudiaf A (1996) Etude sismotectonique de la region d'Alger et de la Kabylie (Algérie). Ph.D. Dissertation, Université Montpellier II, p 274

Casapulla C, D'Ayala DF (2006) In plane collapse behaviour of masonry walls with frictional resistance and openings. In: Lourenço PB, Roca P, Modena C, Agrawal S (eds) Structural analysis of historical constructions. Possibilities of numerical and experimental techniques. Proceedings of the 5th International Conference, Macmillan India Ltd, New Delhi, pp 1153-1160

CEN (2005) Eurocode 8: design of structures for earthquake resistance. Part 3: assessment and retrofitting of buildings. EN 1998-3, March 2005

CNERU: Centre National d'Etudes et de Recherches appliquées en Urbanisme (2008) Permanent plan to safeguard the Casbah of Algiers conducted by the Algerian Ministry of Culture, September 2008

D'Ayala D (2005) Force and displacement based vulnerability assessment for traditional buildings. Bull Earthq Eng 3:235-265

D'Ayala D (2013) Assessing the seismic vulnerability of masonry buildings. In: Tesfamariam S, Goda K (eds) Handbook of seismic risk analysis and management of civil infrastructure systems. Woodhead Publishing, Cambridge, UK, pp 334-365. doi:10.1533/978057098986.3.334

D'Ayala D, Ansal A (2012) Non-linear push over assessment of heritage buildings in Istanbul to define seismic risk. Bull Earthq Eng 10(1):285-306

D'Ayala D, Novelli V (2011) Deliverable D17: correlation of limit states and damage levels for types of buildings. Perpetuate project (www.perpetuate.eu)

D'Ayala D, Speranza E (2003) Definition of collapse mechanisms and seismic vulnerability of historic masonry buildings. Earthq Spectra 19(3):479-509

Erdik M, Fahjan Y (2006) Damage scenarios and damage evaluation, assessing and managing earthquake risk heo-scientific and engineering knowledge for earthquake risk mitigation: developments, tools, techniques. In: Olivera CS, Roca A, Goula X (eds) Book series: geotechnical, geological, and earthquake engineering, vol 2, Chap 10. Springer, Berlin

Fajfar P (2000) A non-linear analysis method for performance-based seismic design. Earthq Spectra 16(3):573592

Geomatrix Consultants Inc. and Centre National De Recherche Appliquee en Génie parasismique (CGS) (1998) Probabilistic hazard assessment of the Algiers region: "UNCH project No. ALG/92/003. Technical report submitted to United Nation Centre for Human Settlements, Nairobi, Kenya, plus Tables, figures and plates, pp 53

Giardini D, Grunthal G, Shedlock KM (1999) The GSHAP global seismic hazard map. Ann Geofis 42(6):12251230 
Giovinazzi S, Lagomarsino L (2004) A macroseismic method for the vulnerability assessment of buildings. 13th world conference on earthquake engineering, Vancouver, BC, Canada, August 1-6

Groupe CNERU (2009) Plan de recollallment, and codification: ES 1 / DEG / 01 / 09 / CA

Hamdache M, Pelaéz JA, Talbi A (2010) A unified catalog of main earthquakes for Northern Algeria from A.D. 856 to 2008. Seismol Res Lett 81:732-739

Jaiswal K, Wald D, D’Ayala D (2011) Developing empirical collapse fragility functions for global building types. Earthq Spectra 27(3)

Lagomarsino S, Penna A, Galasco A, Cattari S (2013) TREMURI program: an equivalent frame model for the nonlinear seismic analysis of masonry buildings. Eng Struct 56:1787-1799

Lagomarsino S, Abbas N, Calderini C, Cattari S, Rossi M, Ginanni Corradini R, Marghella G, Mattolin F, Piovanello V (2011) Classification of cultural heritage assets and seismic damage variables for the identification of performance levels. In: Proceedings of structural repairs and maintenance of heritage architecture conference (STREMAH), WIT Press, ISSN 1743-350, pp 697-708

Meghraoui M, Philip H, Albarede F, Cisternas A (1988) Trench investigations through the trace of the 1980 El-asnam. Thrust-fault_evidence For paleoseismicity, Bssa. Bull Seismol Soc Am 78:979-999

Missoum S (2003) Alger A L'Epoque Ottomane. La Medina Et La Maison TraditionnellePublished by Edisud, pp 263-271

Modena C, Valluzzi MR, da Porto F, Casarin F (2011) Structural aspects of the conservation of historic masonry constructions in seismic areas: remedial measures and emergency actions. Int J Archit Herit 5(4-5)

Monelli D, Pagani M, Weatherill GA (2012) The hazard component of openquake: the calculation engine of the global earthquake model. In: Proceedings of the 15th world conference on earthquake engineering, Lisbon, Portugal, paper n. 4180

Muthukumar S, Desroches R (2004) Evaluation of impact models for seismic pounding. 13th world conference on earthquake engineering. Vancouver

Novelli VI, D’Ayala D (2014) LOG-IDEAH: LOGic trees for identification of damage due to earthquakes for architectural heritage. Bull Earthq Eng. doi:10.1007/s10518-014-9622-0

Novelli V, D’Ayala D (2010) Manual of FaMIVE. Deliverable 27 Perpetuate project(www.perpetuate.eu)

Peláez J A, Hamdache M, López Casado C (2006) Seismic hazard in terms of spectral accelerations and uniform hazard spectra in Northern Algeria. Pure Appl Geophys 163:119-135. doi:10.1007/s00024-005-0011-0

Olivera CS, Peláez JA, Hamdache M (2005) Updating the probabilistic seismic hazard values of northern Algeria with the 21 May 2003 M 6.8 Algiers earthquake included. Pure Appl Geophys 162:2163-2177

Ramos LF, Lourenco PB (2004) Modelling and vulnerability of historical city centre in seismic areas: a case study in Lisbon. Eng Struct 1295-1310

Vicente R, D’Ayala D, Ferreira T, Varum H, Costa A, da Silva J, Lagomarsino S (2014) Seismic vulnerability and risk assessment of historic masonry buildings. In: Costa A, Guedes JM, Varum H (eds) Structural rehabilitation of old buildings, Springer-Verlag, Berlin, Heidelberg, pp 307-348. doi:10.1007/ 978-3-642-39686-1_11 